\title{
The effect of hypnotic anaesthesia on cortical responses
}

\author{
A: M. HALLIDAY ${ }^{1}$ AND A. A. MASON \\ From the Department of Psychological Medicine, The National Hospital for Nervous Diseases, Queen Square., \\ London
}

The phenomenon of hypnotic anaesthesia has been well established for over a century, since Esdaile (1846) published his original account of 73 surgical operations carried out painlessly under hypnosis, and the technique has established a modest, but definite, place in contemporary medicine and dentistry (Mason, 1960, 1964). In view of this, it is surprising how little is known of the physiology of the hypnotic state. Studies of the E.E.G. during hypnosis, reviewed by Ellingson (1956) and by Barber (1961), suggest that there is no specific change in the background activity, the record showing a normal waking pattern unless the subject actually appeared to go to sleep or was put to sleep by suggestion, when a typical sleep record supervened.

There have been several investigations of the physiological responses to painful stimuli under hypnosis, recording such measures as changes in the pulse rate and respiration, vasomotor responses, or facial flinching. The literature has been reviewed by Gorton (1949) and Barber (1961), but this work and some other papers (Das, 1958; Black and Wigan, 1961 ; Black, Edholm, Fox, and Kidd, 1960; Barber and Hahn, 1962) have added little to our understanding of the mode of action of hypnotic suggestion in producing a loss of sensibility, although they substantiate the existence of differences in the objective responses to 'painful' stimulation in the hypnotic state.

Dawson (1958b) suggested that the loss of sensation under hypnosis might be associated with blocking or gross attenuation of the afferent sensory volley before it reached the cortex. There are centrifugal fibres going from the cortex to the synapses in the sensory pathways and it is known that a conditioning stimulus to the cortex can greatly reduce the size of the post-synaptic response to a test stimulus, given peripherally. Dawson himself, for instance (1958a), recording the post-synaptic response to a stimulus to the forepaw of the rat, found that it could be reduced to $50 \%$ of its original size by a

${ }^{1}$ Member of the external staff of the Medical Ressarch Council. preceding stimulus to the contralateral receiving are产 of the somato-sensory cortex. Satterfield (1962) has recently reported comparable findings in the cato Similar centrifugal effects, in which the size of aff afferent test volley is modified following cortica $\vec{\Phi}$ discharges, can be recorded at the somato-sensory synapses in the thalamus (Ogden, 1960). Such centri $\omega_{\infty}$ fugal control appears to exist for most, if not all, of the other sensory inputs (Livingston, 1959), ant attenuations even larger than the $50 \%$ observed bis Dawson and Satterfield have been recorded in som $\$$ afferent pathways (Desmedt, 1963).

If loss of sensation under hypnotic suggestion is brought about by attenuation of the afferent volnefy it should be possible to detect the resultant reduction or abolition of the evoked response in the primary cortical receiving area. This cortical response can 3 . recorded in conscious human subjects through ser. face electrodes by an averaging technique, and wlổ there are normally variations in its form and amplis tude, quite apart from hypnosis, any large changes in amplitude associated with the loss of sensation during hypnotic anaesthesia should be readily detect able. Moreover, hypnotic anaesthesia is particularl迎 favourable for investigation because it is under the experimenter's control and can be turned on and off in successive runs, thus permitting a check of test $\overrightarrow{\overrightarrow{0}}$ retest reliability of the results.

In the present experiments, cortical evoked responses have been investigated in nine subjects. before, during, and after hypnotic anaesthesia hat been suggested. A preliminary description of the findings has already appeared (Halliday and Masoni 1964).

\section{MATERIAL}

Nine volunteer subjects took part in the investiga tion, eight female and one male. All had beet hypnotised previously, and analgesia to pin-prick had been successfully produced. They included of medical student, a dental student, a nurse, an almoner, and five patients, three of whom were being 300 
treated by hypnotic suggestion for asthma, one for hay fever, and another for headaches.

EXPERIMENT 1: SPECIFIC CORTICAL RESPONSES TO ELECTRICAL STIMULATION OF THE FINGERS

In five subjects, the specific evoked response was recorded from an electrode over the post-central gyrus following electrical stimulation of the contralateral index and middle fingers.

METHODS Condenser discharges were delivered via an isolating transformer through ring electrodes on the index and middle finger of one or other hand, and the evoked responses were recorded through a scalp electrode over the surface marking of the contralateral hand area in $S_{1}$ with reference to another electrode $7 \mathrm{~cm}$. anterior. Average evoked responses were recorded using an electromechanical averager (Dawson, 1954), as described in a previous investigation (Halliday and Wakefield, 1963). At the beginning of each session, the strength of the electrical stimulus just felt by the subject was determined and a stimulus of at least twice this threshold intensity was used during the session. The strengths used (except in certain specific runs during which stronger stimuli were tested) were such as would have been comfortably tolerated by any healthy subject and did not feel painful or unpleasant to our subjects in the unhypnotised state. The stimulus had a time constant of 10 or $20 \mu \mathrm{sec}$. It was repeated regularly at a frequency of one per second, except in the first subject, where a two-second interval was used. The faster repetition rate was adopted in the subsequent subjects in order to keep the sessions as short as possible (they usually lasted about three hours), and because control runs suggested that the response was not significantly attenuated at the higher rate. In any one run, the average response to 66 or 132 such stimuli was recorded.

In an initial run, simultaneous recordings were made from electrodes on corresponding points on the two sides of the head; each channel of the averager recorded with a duration of $100 \mathrm{msec}$. and a unilateral stimulus was given to one hand $10 \mathrm{msec}$. after the beginning of the record. This initial run served as a check that the response was being recorded contralaterally to the stimulus. Thereafter the two channels of the averager were used consecutively with a $10 \mathrm{msec}$. overlap, both recording from the contralateral scalp electrodes. As each had a duration of $100 \mathrm{msec}$. and the stimulus occurred $10 \mathrm{msec}$. after the first channel began recording, an average record was obtained of the activity occurring during the $180 \mathrm{msec}$. immediately following the stimulus.

During a scssion, several runs were first recorded with the subject unhypnotised and feeling the stimulus normally. The subject was then hypnotised by the method of progressive relaxation (Wolberg, 1948) as modified by Mason (1960). The subject was assumed to be in a hypnotic trance when the eyes closed in a typical cataleptic manner-a progressively accelerating repetitive blink ending in a flutter. Some further records of the averaged evoked response were taken in the hypnotic state. After this, anaesthesia was induced by the hypnotist, the stimulus being given continuously once per second during this period. It was suggested to the subject that the stimulated hand would become 'numb and frozen', that all feeling would be lost from the hand and that the electrical pulses would disappear. The subject was instructed to let the hypnotist know when he could no longer feel them by raising the index finger of the other hand. When he had indicated that this was so, the average response was recorded to a further run of stimuli. A number of subsequent runs were given, before each of which sensation in the hand was either brought back or abolished by suggestion, and the subject was asked to confirm before each run that the suggestion had been successful. Reports were also taken both at the end of runs and subsequently when the subject had been dehypnotised. At the end of the session a further control run was usually recorded with the subject fully dehypnotised and feeling the stimulus normally.

RESULTS Representative records obtained from the first subject (B.K.) are shown in Figure 1. An evoked potential of normal latency and wave-form is seen in the two initial records, taken before the subject was hypnotised, although in $(b)$ it is somewhat obscured by muscle artefact. This subject was rather tense and anxious at this time. Records $(c)$ and $(d)$ were taken after she had been hypnotised and told to relax, and show the evoked response apparently unaltered in this state. After this, loss of sensation in the left hand was suggested. The hypnotist (A.A.M.) was surprised at how difficult it was to abolish perception of the electrical stimulus as compared with previous experience with pin-prick. It took approximately three minutes of suggestion before this subject reported that she could no longer feel the electrical pulses at all. Records $(e)$ and $(f)$ were taken at this time, and show that the early part of the evoked response is still clearly present and apparently unaltered in size. The later surfacenegative components, occurring between 60 and $100 \mathrm{msec}$. after the stimulus, have disappeared, but reappeared in a further run in which the stimulus strength was doubled, although the subject was still reporting that she could not feel the stimulus $(g)$. It seems, therefore, that there is no correlation between the disappearance of these waves and non-perception of the stimulus. After a further run under hypnosis at the original intensity of stimulation $(h)$, the subject was dehypnotised and the last control run taken. This record $(i)$ was marred by heavy muscle artefact throughout, and this probably accounts for the apparent diminution in the average response.

In another subject (K.B.K.), it took approximately four minutes' persistent suggestion under hypnosis to induce anaesthesia to the electrical stimuli in the right hand, but the anaesthesia could then be readily turned on and off in successive runs. In each run the 


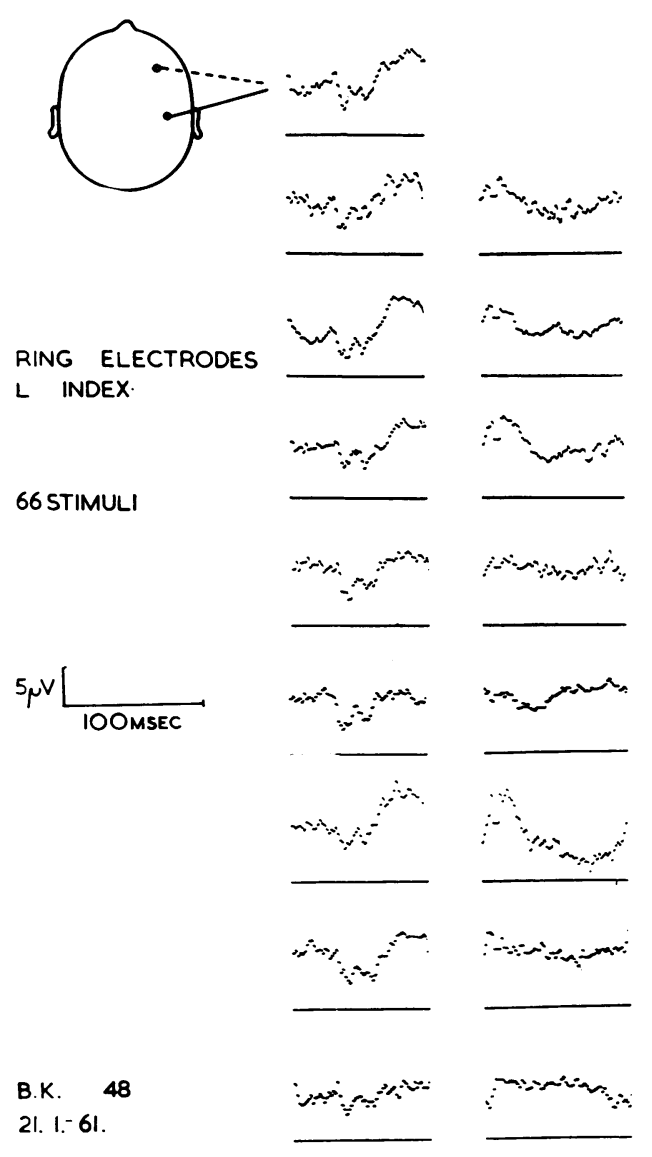

(a) before hypnosis

(b) before hypnosis (muscle artefact)

(c) hypnotised but feeling stimulus

(d) hypnotised but feeling stimulus

(e) suggested loss of feeling

$(f)$ suggested loss of feeling

(g) suggested loss of feeling (stimulus strength doubled)

(h) suggested loss of feeling

(i) dehypnotised and feeling stimulus (muscle artefact)

FIG. 1. Recordings of the averaged cerebral evoked responses in subject B.K. to 66 electrical stimuli of the digital nerves of the contralateral index finger given once every two seconds. In each record the stimulus was givers $10 \mathrm{msec}$. after the first channel of the averager (left-hand trace of each pair) had begun recording. The second channe of the averager (right-hand trace of each pair) began recording 10 msec. before the end of the first channeक record, i.e., 80 msec. after the stimulus, except in the first record (a) where this channel was used to record from thB contralateral cortex (trace not shown). The pair of traces on each line thus represents a record of the average\$ cerebral activity for the $180 \mathrm{msec}$. immediately following the stimulus. Relay switching artefacts at the beginning and end of the sweeps should be ignored. Three ordinates in each channel are earthed and serve as a reference voltage 3 In records $(b)$ and $(i)$ the responses are somewhat obscured by muscle artefact, due to the tenseness of the subject.

average response to 132 stimuli was recorded. Even with this relatively large number of stimuli in each run, there was considerable variation in the size and form of the average response during the course of the experiment, as seen in Figure 2. However, there is no tendency for the potential to be consistently reduced during the runs in which the stimuli were not felt $(c, e$, and $h)$ as compared with the runs during which normal sensation was restored $(d, f$, and $i$ ). In one run, it was suggested to the subject that the stimulus (given on the right hand) would feel much stronger, though the objective strength was, in fact, unchanged. She was told: 'The impulses you feel will get much stronger and sharper. It will be bearable, but much stronger and sharper. Keep relaxed, but raise the finger of your left hand when you feel that they get stronger and sharper'. Afte․ㅡ. she had confirmed that they had done so, the record was taken (Fig. $2 g$ ). The averaged response was not significantly increased in size. However, too mucb weight should not be put on this negative finding, as a small objective increase in the stimulus strengt in a subsequent run (not shown) also failed to increase the size of the response significantly.

Three other subjects were recorded in the same way. Two of them gave essentially similar results tô 


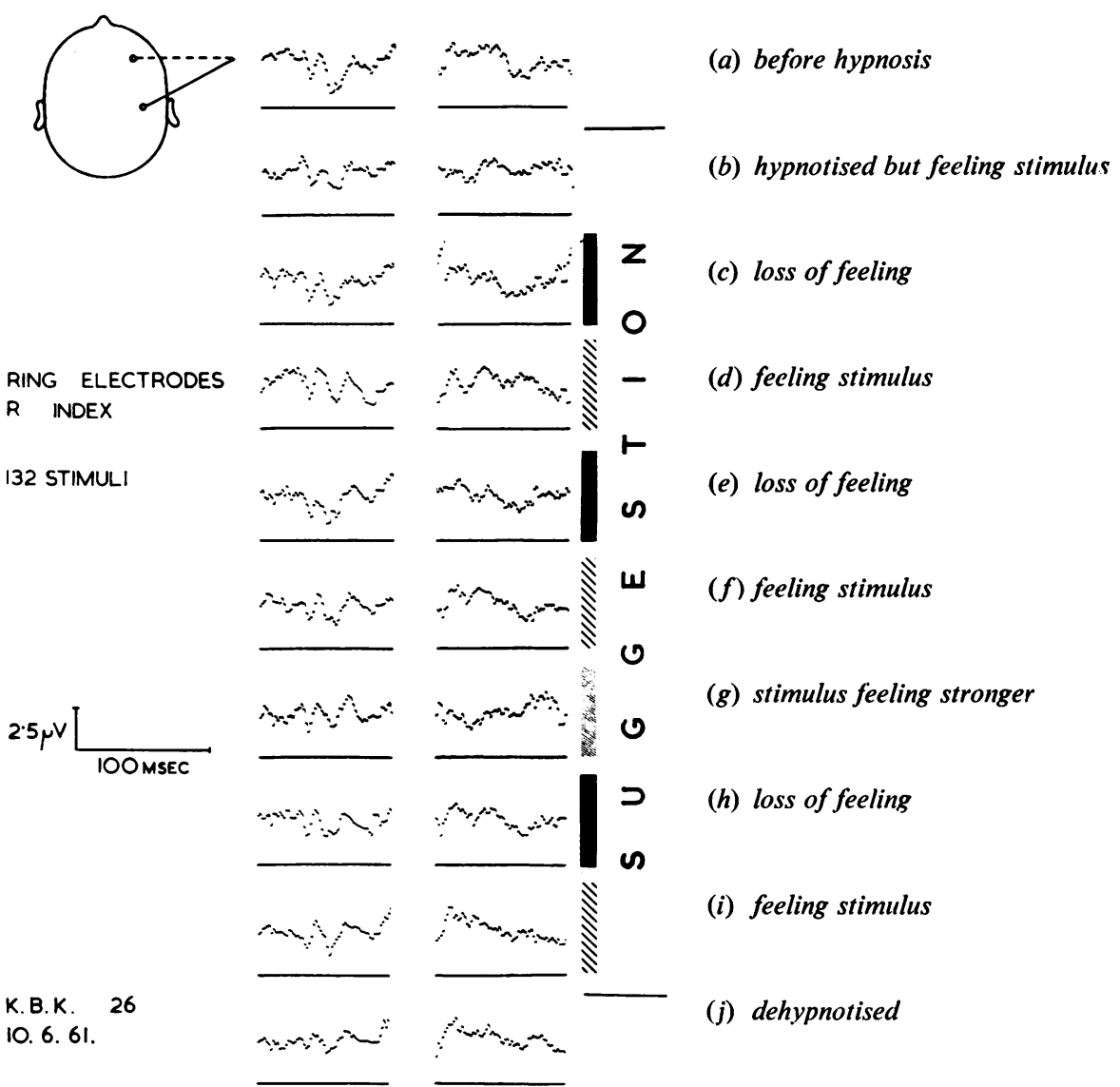

FIG. 2. Averaged cerebral evoked responses in subject K.B.K. to 132 electrical stimuli to the right index finger, given once per second. Responses were recorded (a) before hypnosis and $(b)$ after hypnosis. Thereafter, the subject could be made to feel or not to feel the stimulus at will, by direct suggestion under hypnosis. The nature of the suggestion given before each record is indicated on the right and its success was in each case confirmed by the subject's reports. Before one of the records $(g)$ it was suggested that the stimulus would feel much stronger than before, though its objective strength was in fact unaltered. The final record $(j)$ is a control taken after hypnosis had been abolished when the subject was reporting feeling the stimuli normally.

the two already described, in that there were cortical evoked responses clearly present when they reported that they could not feel the stimuli. The other subject was less successful in two ways. The records of the evoked potentials were unsatisfactory because of an obtrusive alpha activity which appeared to become locked to the stimulus and partly obscured the response; further, although a response was clearly recorded after anaesthesia had been suggested, this subject reported subsequently that she had still felt the electrical pulses 'in her mind but not in her fingers', but that she had felt quite detached from them. It would, therefore, seem impossible to put any weight on the results in her case.

Thus, in four out of five of these subjects, stimu- lated electrically, it had been possible to induce complete hypnotic anaesthesia to the stimulus and in all of them an apparently normal and unattenuated response was recorded under these circumstances.

\section{EXPERIMENT 2: SPECIFIC CORTICAL RESPONSES TO} MECHANICAL STIMULATION OF THE FINGERS

The sensation produced by the electrical stimulus had proved unexpectedly difficult to abolish by hypnotic suggestion and it seemed reasonable to question whether this might be related to the 'unphysiological' nature of the stimulus. Electrical stimuli are unlike more natural forms of stimulus in at least one important respect. They stimulate the fibres of the 

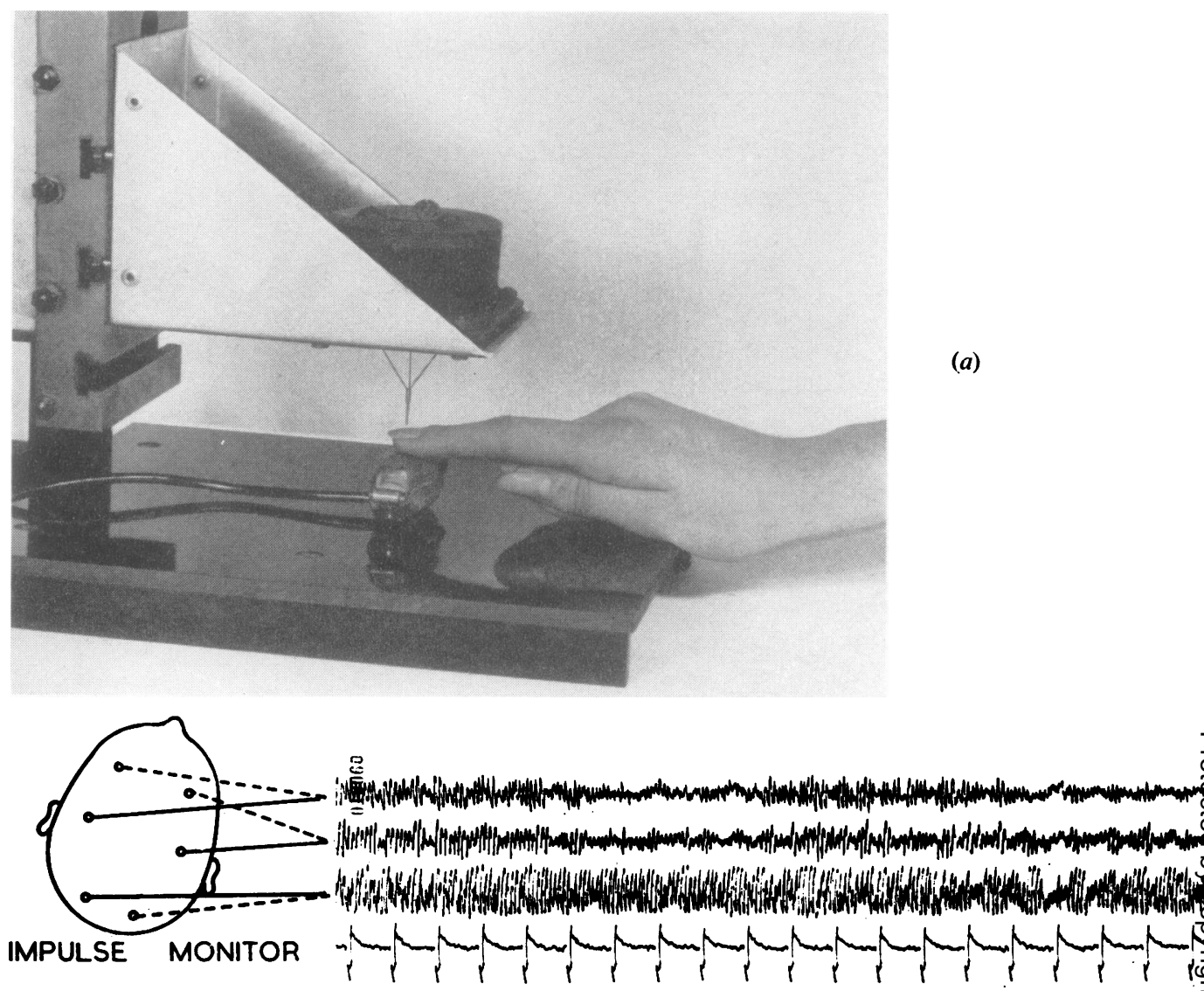

IMPULSE MONITOR

STIMULUS MARKER

FEELING STMULUS

seconds

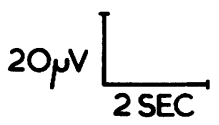

M. W.

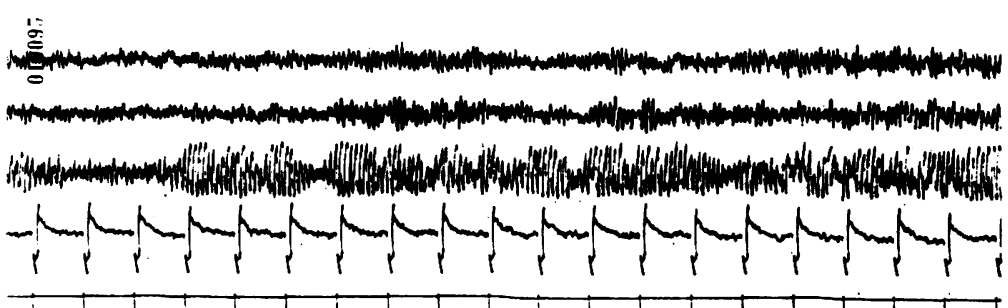

4. II. 61 .

HYPNOTISED

NOT FEELING STIMULUS

FIG. 3. (a) The electromechanical transducer used to deliver tap stimuli to the nail or pad of the index finger the second experiment. The finger rests on a crystal microphone which monitors the transmitted impulse.

(b) Example of the continuous record taken with a conventional E.E.G. while averaging the cerebral evokedo responses to a mechanical stimulus. The time of the stimuli, given once per second, is marked in the fifth channel, while the fourth channel is a record of the impulse transmitted through the finger to the crystal microphone. At the bottors of the record is a time trace in seconds. The top two channels are recording from the same two pairs of electrodeస్ as were being used to record evoked responses, the third channel from a pair of occipital electrodes. Both records shown here were taken with the subject hypnotised, in (a) before, and in (b) after hypnotic anaesthesia had been induced. 
peripheral nerve trunk according to their size and electrical threshold and irrespective of the kind of sensation normally carried by the fibres. On the original hypothesis, the mechanisms controlling the size of the afferent inflow at the sensory synapses might well be organized to deal with natural forms of stimulation travelling up by pathways subserving a particular sensory modality. Electrical stimulation might by-pass these mechanisms by travelling up in a heterogeneous array of fibres, the expected effect not being observed even though some part of the volley was being attenuated. It was, therefore, decided to repeat the observations on evoked potentials during hypnotic anaesthesia using a more natural form of stimulus. The specific evoked response was therefore recorded in the same way in three further subjects, but using mechanical instead of electrical stimulation of the fingers, according to the technique introduced by Sears (1959).

METHODS Sharp taps were given to the nail or the pad of the index finger by means of an electromechanical transducer (Fig. 3a) and the effective strength of these tap stimuli was monitored by means of a crystal microphone on which the finger rested. This allowed a record of each transmitted impulse to be taken throughout the runs
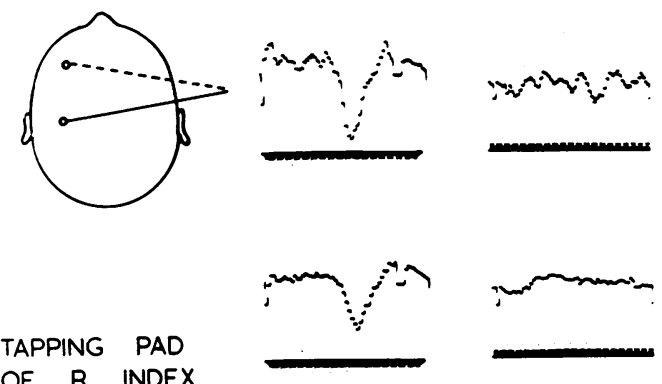

TAPPING PAD

OF $R$ INDEX

I32 STIMULI

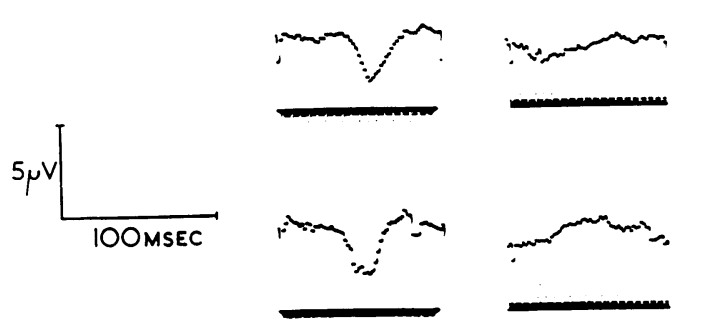

(a) before hypnosis

(Fig. $3 b$ ) and it was possible to check that there had not been any diminution or increase in the effective stimulus strength due to small movements of the finger or displacement of the stimulator. The procedure was otherwise the same as that employed in the first experiment.

RESULTS Complete loss of sensation was successfully induced under hypnosis in two of the three subjects: the third subject reported the taps as definitely weaker, but still perceptible. This last subject had a response of low amplitude which remained present throughout the session and was not appreciably altered by the suggested anaesthesia or by suggestion that he would feel the tap more strongly, but, as complete anaesthesia was not induced, the results are inconclusive. The other two subjects both had large responses. Representative runs from the various stages of the experiment with these two subjects are shown in Figures 4 and 5 . In both of them, there were some small changes in the amplitude and form of the averaged responses to the tap stimuli from run to run, but these are within the limits of normal variation for this type of stimulus, and the response is not abolished, nor even greatly reduced, at the time of the hypnotic anaesthesia. There was

(b) hypnotised but feeling stimulus

(c) suggested loss of feeling

(d) suggested feeling more strongly

A.E. 31

28. 10.61 .

FIG. 4. Recordings of the averaged cerebral evoked responses in subject A.E. to 132 tap stimuli to the pad of the right index finger, given once per second. Record $(d)$ was taken after it had been suggested that the stimulus would feel stronger, although its strength actually remained unchanged. 


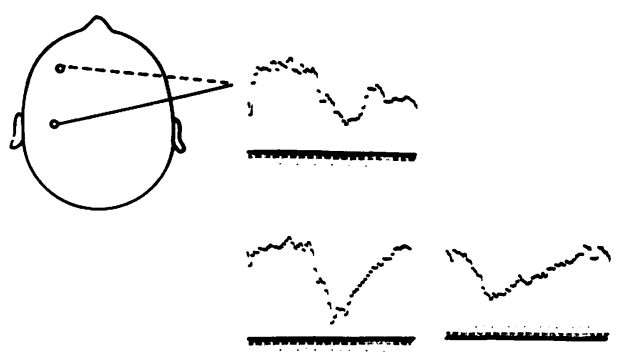

(a) before hypnosis

TAPPING PAD

OF $R$ INDEX

66 STIMULI
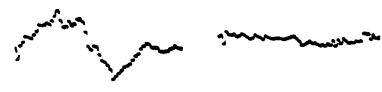

(c) suggested loss of feeling

(b) hypnotised but feeling stimulus

(d) suggested loss of feeling

(e) suggested feeling

$(f)$ suggested feeling more strongly

FIG. 5. Recordings of the averaged cerebral
the right index finger, given once per second.

also no significant change in amplitude when it was suggested that the stimuli would feel stronger.

The results are, therefore, essentially the same as those of the first experiment and confirm the persistence of the specific evoked potential without attentuation during hypnotic anaesthesia. This is seen equally clearly with either electrical or mechanical stimulation.

EXPERIMENT 3: NON-SPECIFIC (VERTEX) RESPONSES TO AUDITORY STIMULATION

In a further experiment, it was decided to explore the behaviour of a non-specific cortical evoked potential during hypnotic anaesthesia. Such a response can be recorded from a scalp electrode situated over the vertex, in response to single stimuli given in a variety of sensory modalities (Larsson, 1956). It appears characteristically as a surface negative wave with a peak latency of approximately $100 \mathrm{msec}$. and a phase reversal at the vertex electrode. It is large enough in relation to the background activity to be detectable without recourse to averag ing, so that either single responses or the super $\bar{\partial}$ imposed responses to a small number of stimuli cant be recorded directly by photographing the E.E.G $\stackrel{\mathbb{Q}}{\AA}$ displayed on an oscilloscope. It can be evoked by electrical stimuli to a peripheral nerve (Larsson $\frac{0}{3}$ 1953), but click stimuli are more consistently effec tive, and are best given irregularly and at an intervab of more than 10 seconds, as the response tends to become refractory at shorter interstimulus intervals and is larger if the stimulus is unexpected.

The non-specific vertex response was recorded in four subjects, before and during hypnosis and again after hypnotic deafness had been suggested. Hypnotic deafness was successfully produced for some part of the experiment in three of the foursubjects, though in no case was it possible to abolish the perception of the click stimuli completely=. throughout a whole run of stimuli. However, since the responses were recorded individually, this is not so important as in the first two experiments. 
METHOD Loud click stimuli were delivered through earphones (S. G. Brown, type F) into both ears of the subject. They were generated by condenser discharges of a longer time constant and higher voltage than that used for the finger stimulus $(250 \mu \mathrm{sec} .300 \mathrm{~V})$. Successive stimuli were given at irregular intervals of between 10 and 45 seconds. Responses were recorded on two E.E.G. channels from a bipolar chain of three electrodes, the centre one at the vertex and the other two $4 \mathrm{~cm}$. anterior and posterior to it respectively in the mid-sagittal plane. The responses were recorded either singly or by photographic superimposition from an oscilloscope which was triggered either at the same time as the stimulus or $10 \mathrm{msec}$. before it.

RESULTS Figure 6 shows the superimposed responses to 10 click stimuli recorded in one subject $(a)$ before the subject was hypnotised, $(b)$ after hypnosis, but with the subject still hearing, (c) following suggestions that the clicks could not be heard, and $(d)$ after hearing had been restored.

Before beginning record $(c)$, the subject had indicated that she could no longer hear the clicks, but on being asked for a further report at the end of the run, after she had been dehypnotised, she said that the clicks had not completely disappeared, though they were very much fainter. It will be seen that there is some progressive diminution in the amplitude of the vertex response throughout the experimental session (especially seen in the response recorded from the posterior pair of electrodes). This can be put down to the well-known habituation of this response to repeated stimuli. The non-specific response is still present at all stages of the experiment, even in the runs in which the stimuli were perceived as much fainter.

In a further subject, similar records were taken of the superimposed responses to 10 clicks, but in addition, the first five responses in each run were recorded individually. The results are illustrated in Figure 7. After being recorded in the hypnotic state, when clear vertex responses were obtained (Fig. 7a), the clicks were repeated regularly once every second while deafness was being suggested. The subject was told: 'You will get deafer and deafer so that you don't hear the clicks at all. Your hearing will not come back again until I squeeze your left hand'. When she had indicated by raising the finger that she could no longer hear them, a further run was recorded with irregular stimuli (Fig. 7b). Again clear vertex responses are seen. The subject reported following this run: 'It had faded away and I could hear nothing, and then I heard something very far

\section{V.P.L. 22}

7. 10.61 .

CONTROL

HYPNOTISED

\section{SUGGESTED DEAFNESS}

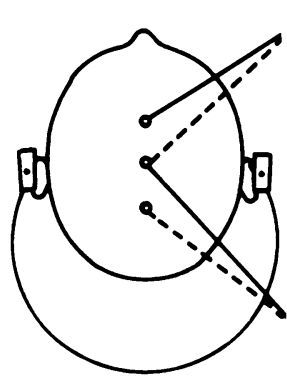

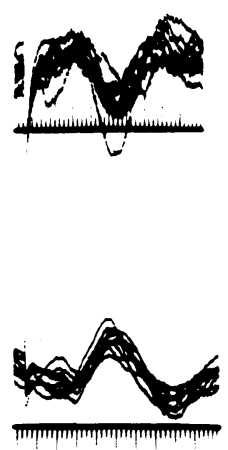

(a)
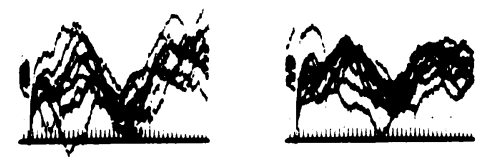

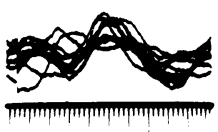

(b)

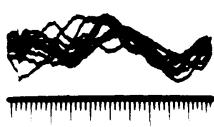

(c)
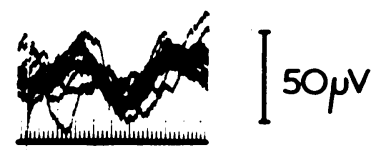

HEARING

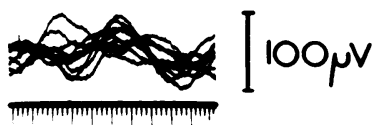

(d)

FIG. 6. Superimposed records of the non-specific (vertex) responses to 10 loud click stimuli given at irregular intervals varying from 10 to 45 seconds. Subject V.P.L. The records were taken (a) before hypnosis, (b) after hypnosis but with the subject still hearing the click, (c) after hypnotic deafness had been suggested and at a time when the subject subsequent'y reported the clicks as being very much fainter, $(d)$ when normal hearing had been restored.

Stimulus given 10 msec. after the start of the sweep. Time scale in 5, 20, and 100 msec. intervals. 


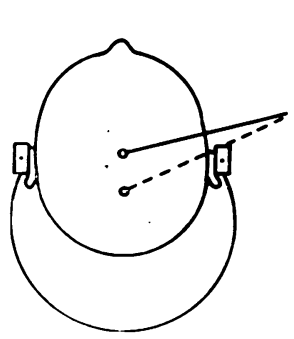

HYPNOTISED

SUGGESTED DEAFNESS

DE - HYPNOTISED
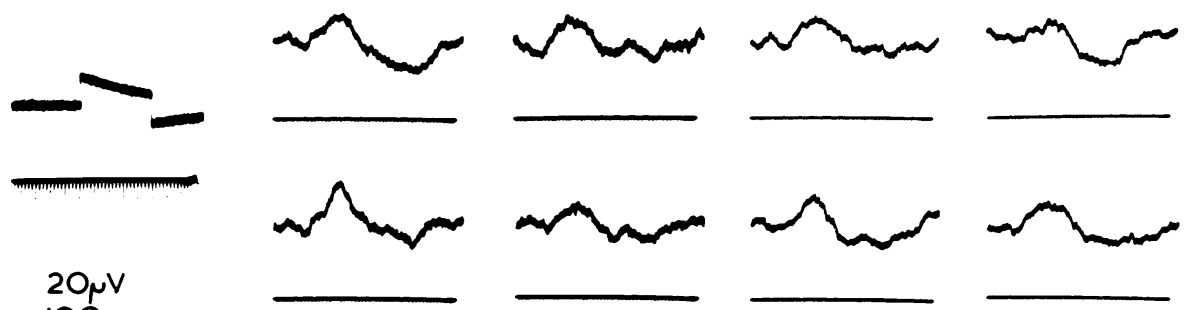

$20 \mu V$
IOOMSEC
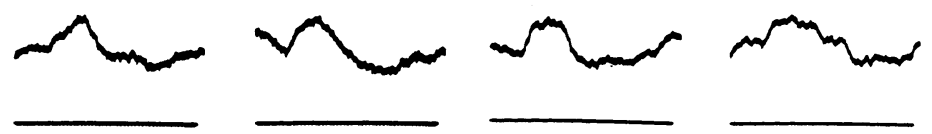

A.E. 31

28. 10. 61 .

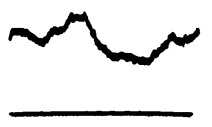

(a)

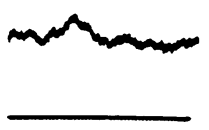

(b)

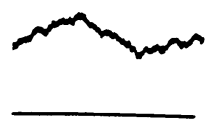

(c)

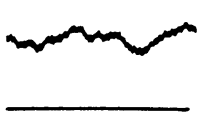

(d)

FIG. 7. The five lower records in each of the four columns are the non-specific (vertex) responses to the first five individual click stimuli in the run concerned, while above them is a record of the superimposed responses to 10 clicks given subsequently in the run. Subject A.E. The responses were taken (a) with the subject hypnotised but hearing normally, (b) and (c) after hypnotic deafness had been induced and the subject was reporting that the click was very faint and 'far away', and (d) after the subject was dehypnotised, when she was again hearing the clicks normally. Stimulus coincident with start of the sweep.

away, but not the click'. A second run was then attempted. The subject was told: 'It will go completely again; your hearing will get less and less until the click goes completely and you will let me know when you no longer hear the clicks'. Further records were taken when the subject had indicated that this had happened (Fig. $7 c$ ). At the end of the run, the subject reported: 'It was the same, I didn't feel it going away altogether. It was further away, like at the end of a long tunnel, but it sometimes seemed half way'. She said that the only time at which she had heard nothing was at the beginning of the first run. Clear vertex responses are seen in the records of both these runs, and it is of particular interest that the single clicks at the beginning of the first run with hypnotically-induced deafness are producing cleat non-specific responses. These are apparently occuro ring at the time when the subject reported hearing nothing at all.

A further subject reported that while she was nof able to hear the clicks during the runs in which deaf ness had been suggested, she had heard 'a blurre ${ }^{\circ}$. something' there once or twice during the run. She was instructed to report any stimulus she perceived by raising her finger, and the responses were recorded individually. During a run of 20 stimuli, of which sh reported perceiving only two, definite non-specifieresponses were recorded on 12 occasions. The tw\% stimuli perceived produced negligible responses, not in any obvious way distinguishable from those t\$ 
other unheard stimuli. It is of particular interest that the responses were larger in some of the trials in which the subject did not hear the click than in the two trials in which the clicks were heard. These results seem to establish clearly that there is no correlation between the ability of a stimulus to produce a non-specific vertex response and its relative perceptibility during hypnotic anaesthesia.

\section{DISCUSSION}

It was originally suggested by Adrian (1954) that when incoming sensory stimuli are not being attended to, the corresponding afferent signals may be attenuated even before they arrive at the cerebral cortex. Pointing out that 'the signals from the sense organs must be treated differently when we attend to them and when we do not', he went on to question 'whether the afferent messages which can evoke sensation are allowed at all times to reach the cerebral cortex or are sometimes blocked at a lower level'. Hernandez-Péon, Scherrer, and Jouvet (1956) subsequently produced evidence that electrical responses to click stimuli recorded in the cochlear nucleus of the cat were reduced in size when the animal's attention was distracted by concomitant visual, olfactory, or somatic stimulation, and similar results have been obtained in recordings of the photicallyevoked response in the cat's optic tract during acoustic or olfactory stimulation (Hernandez-Péon, Guzmán-Flores, Alcaraz, and Fernández-Guardiola, 1957). These results have been criticized and alternative explanations have been put forward (Horn and Blundell, 1959; Horn, 1960; Hugelin, Dumont, and Paillas, 1960), but they establish a strong prima facie case for the view that the afferent signals which are not being attended to are attenuated at the synapses of the ascending sensory pathway. Even stronger evidence in favour of this view comes from experiments by Hernandez-Péon and Donoso (1957) and Jouvet (1961). The former authors recorded the evoked response to flashes in four waking patients by electrodes implanted in the occipital lobe. They found that the potential varied in size with the amount of attention that was being paid to the stimulus, and that it was reduced or abolished when the patient concentrated on solving an arithmetical problem or recalled a visual image. One particularly suggestible patient reported changes in the intensity of the flash stimulus (which was actually constant) following verbal suggestion, and the size of the recorded potential varied in parallel with these subjective changes in stimulus intensity. The authors did not attempt to induce complete blindness by suggestion, but the similarity of these experiments to the present ones on hypnotic anaesthesia is obvious.
Jouvet (1961) has made similar recordings of flashevoked responses from the optic radiation in 12 patients, four of whom were suffering from prolonged unconsciousness following head injury. In the eight conscious patients, the evoked responses were enhanced when the patients were asked to count the flashes and they remained enhanced as long as the patient continued to attend to the stimuli. Diverting the attention to olfactory or auditory stimuli, or to mental arithmetic, greatly reduced the size of the visual response and 'nociceptive' stimuli were particularly effective in this respect. However, in one woman with hysterical hemianaesthesia (who therefore denied feeling the painful stimuli) even very strong nociceptive stimulation had no effect, although auditory stimulation was effective. Nociceptive stimulation was equally ineffective in influencing the visual responses in the unconscious patients. Though these recordings, like those of Hernandez-Péon and Donoso, were made on the photically-evoked response, in three other patients Jouvet also recorded the response to mechanical tapping of the skin by a tendon hammer by means of an electrode stereotactically implanted in the region of the nucleus ventralis postero-lateralis in the thalamus. It was not possible to do such thorough testing in these cases as the time available was limited, but essentially similar results were obtained. When the patient's attention was diverted to mental arithmetic, a very significant decrease of amplitude in the somatosensory response was produced.

There are a number of important differences between these experiments and the present ones. Hernandez-Péon and Donoso and Jouvet obtained their results by recording individual evoked responses in the afferent sensory pathways by means of an implanted electrode. Our own records are average responses from the cortex obtained from scalp electrodes. All our experiments on the specific evoked response have been on the somato-sensory system, while by far the majority of the results reported by Hernandez-Péon and Donoso and by Jouvet concern the visual pathways. However, it is clear that the authors of both these papers regard their results as being representative of a principle applying to other sensory inputs, and Jouvet's experiments on the somatically-evoked response support this interpretation.

In view of this, it is surprising that no significant change in the amplitude of the average response could be produced in our experiments in response to suggestion under hypnosis. If one accepts the conclusion that the size of the evoked response in the particularly suggestible patient of Hernandez-Péon and Donoso varied in parallel with the subjectivelyperceived intensity of the stimulus and that this could 
be readily influenced by verbal suggestion, it is difficult to see how these results can be reconciled with ours, unless the hypnotic state of our subject altered the behaviour of the cortical responses.

There are, however, other circumstances in which the behaviour of the cerebral evoked response does not parallel subjective experience, and in which, as in our experiments, the response may still be present at a time when the stimulus is not being consciously perceived. Among these are hysterical anaesthesia (Alajouanine, Scherrer, Barbizet, Calvet, and Verley, 1958), the 'extinction' of a sensation by contralateral stimulation associated with a parietal lobe lesion (Giblin, 1960), sleep and anaesthesia (Brazier, 1954; Ciganek, 1961; Hagbarth and Höjeberg, 1957). In this connexion, it is of some interest that Jouvet's results on comatose patients and on the patient with hysterical anaesthesia (Jouvet, 1961) suggest that a competing stimulus may have to be consciously perceived in order to be effective in modifying the response to a concomitant stimulus in another modality.

Having established in our first two experiments that there was no change in the amplitude of the specific evoked response in association with hypnotic anaesthesia, we anticipated that there might nonetheless be a significant change in the non-specific (vertex) response. The specific evoked response, recorded over the post-central gyrus, appears to depend exclusively on impulses travelling by the posterior column pathways (Halliday and Wakefield, 1963), while in altered states of consciousness, such as anaesthesia or concussion, it is the impulses travelling in the slower multisynaptic pathways of the anterolateral columns, and particularly the central grey matter of the brain-stem, which are selectively depressed (French, Verzeano, and Magoun, 1953; Arduini and Arduini, 1954; Foltz and Schmidt, 1956; cf. McKenzie and Beechey, 1962). For these and other reasons, discussed elsewhere (Halliday and Mingay, 1961, 1964), it seems likely that the activity of the non-specific pathways projecting diffusely to the cortex has more relevance to perceptual awareness than that in the posterior column pathways, responsible for the specific evoked response. The anatomical pathways mediating the vertex response have not been established, but its non-specific character is well known. Our own experiments on this response show that it is still present during hypnotic deafness and that its size is apparently uncorrelated with whether an auditory stimulus is being heard or not.

The only non-specific evoked response previously studied in association with hypnotic anaesthesia appears to be the alpha-blocking response of the E.E.G. (which also depends upon the diffuse cortical projection system). The majority of the previous investigators of the effect of hypnotic or hysterica blindness upon the alpha rhythm have concluded that the functional blindness did not prevent norma alpha-blocking responses to eye-opening; nor did hypnotically-suggested hallucination of light abolisk the alpha, as did a normal light stimulus (see Gorton 1949 for a review of this work). The same was truep of the pupillary light reflex, which was unaffected bys hypnotic blindness, and was not evoked by suggested light (Lundholm, 1928). On the other hand, Titeca (1938) reports two cases of hysterical hemianaes thesia in which the alpha rhythm failed to block to even very painful stimulation of the skin on the anaesthetic side, while normal blocking response were obtained on stimulation of the unaffected sides This is in contradistinction to the reported finding that the specific cortical response is unaffected in such cases (Alajouanine et al., 1958). We tried to re-

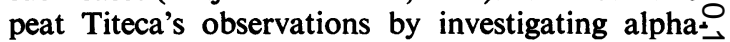
blocking responses in our own subjects as part of the present series of experiments, but abandoned the attempt when we were unable to get satisfactory blocking responses to somatic stimuli even before hypnosis was induced.

The present results provide only negative evidenoes as to the mechanism responsible for the loss of sen tion in hypnotic anaesthesia, but establish that $₫$ part of the loss can be due to attenuation of afferent sensory volleys. Some other evidence mayb $\vec{s}$ cited as supporting the view that the 'sensory loss

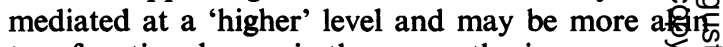
to a functional agnosia than anaesthesia.

Doupe, Miller, and Keller (1939) emphasize important point that in hypnotically induced sensory loss the subject may still be able to discriminate the 'unperceived' object or stimulus from closely similaß objects. The hypnotised subject may, for instance, be deaf to all other voices but the hypnotist's, or mas be induced not to see a particular object or persorg present in the room. Black and Wigan (1961) have recently investigated hypnotically-induced deafnes? to tones of a particular frequency. All these phenomena presuppose the identification of the object not to be seen or the sound which is not to be heard, and this is a task involving a considerable degree of sensory discrimination. It is difficult to see how such highly-selective blocking, which is in marked contrast to complete sensory loss, could be achieved by at tenuation early in the afferent pathways. It is muclo more reminiscent of the type of agnosic defect associated commonly with cortical lesions, where one may have specific objects not perceived because the are not recognized. It is, perhaps, at this functiona年. level that we should look for the operation of the mechanism responsible for hypnotic anaesthesia. The patient with hemiplegia who denies that his paralyse 
arm is his own, and the blind patient with Anton's syndrome who denies the existence of an obvious sensory loss, are suffering from well-recognized sequelae of an organic lesion (Brain, 1961). But in these conditions, as in hypnosis, there is the same difficulty in distinguishing genuine imperception from what appears as a wilful denial of self-evident facts. If we could discover more about the neurophysiology of the process of object recognition, which links sensation to perception, we might be much nearer to understanding the mechanism by which hypnotic suggestion can render certain objects or sensations imperceptible. But it is clear that hypnotically-induced blindness, deafness, or anaesthesia, like anosognosia, is considerably more than mere 'role playing' or the subject simply 'saying he does not feel things', as it is capable of rendering painless major surgery or extraction of teeth.

\section{SUMMARY}

Cortical evoked potentials have been recorded from scalp electrodes in nine subjects before and after hypnosis and while they were reporting that they could not perceive the stimulus following suggested loss of sensation. In five of the subjects, the averaged responses to electrical stimulation of the contralateral hand showed no reduction in amplitude when the subjects were reporting that they could not feel the stimulus, and the same result was obtained in three other subjects in whom the averaged responses to a more 'natural' form of stimulus were recorded (mechanical taps to the contralateral index finger).

In four subjects the non-specific response to auditory stimuli (clicks) was recorded from a surface electrode over the vertex. An attempt was made to induce deafness under hypnosis which was partially successful in three of the subjects. At a time when the clicks were reported as unheard or very faint and far away, apparently normal non-specific responses were being evoked by them.

These results suggest that no part of the loss of sensation in hypnotic anaesthesia can be attributed to attenuation of the sensory messages in the afferent pathways on their way to the cortex. This finding is discussed in relation to other earlier experiments on attenuation of the afferent volley and on the phenomenon of hypnotic anaesthesia.

We should like to thank Professor G. D. Dawson whose averager we used in this investigation, Dr. W. A. Cobb who provided us with facilities in his department, and Mr. H. B. Morton, who gave valuable technical assistance.

\section{REFERENCES}

Adrian, E. D. (1954). The physiological basis of perception. In Brain Mechanisms and Consciousness, edited by J. F. Delafresnaye, pp. 237-248. Blackwell, Oxford.
Alajouanine, T., Scherrer, J., Barbizet, J., Calvet, J., and Verley, R. (1958). Potentiels évoqués corticaux chez des sujets atteints de troubles somesthésiques. Rev. neurol., 98, 757-762.

Arduini, A., and Arduini, M. G. (1954). Effects of drugs and metabolic alterations on brain stem arousal mechanisms. J. Pharmacol. exp. Ther., 110, 76-85.

Barber, T. X. (1961). Physiological effects of 'Hypnosis'. Psychol. Bull. 58, 390-419.

__ and Hahn, K. W. (1962). Physiological and subjective responses to pain-producing stimulation under hypnotically-suggested and waking-imagined 'analgesia'. J. abnorm. soc. Psychol., 65 , 411-418.

Black, S., Edholm, O. G., Fox, R. H., and Kidd, D. J. (1960). The effect of suggestion under hypnosis on the circulatory response to thermal stimuli. J. Physiol. (Lond.), 151, 29-30P.

_ produced by direct suggestion under hypnosis. Brit. med. J., 2, 736-741.

Brain, W. R. (1961). Speech Disorders. Butterworths, London.

Brazier, M. A. B. (1954). The action of anaesthetics on the nervous system. In Brain Mechanisms and Consciousness, edited by J. F. Delafresnaye, pp. 163-199. Blackwell, Oxford.

Ciganek, L. (1961). The EEG response (evoked potential) to light stimulus in man. Electroenceph. clin. Neurophysiol., 13, 165-172.

Das, J. P. (1958). The Pavlovian theory of hypnosis: An evaluation. J. ment. Sci., 104, 82-90.

Dawson, G. D. (1954). A summation technique for the detection of small evoked potentials. Electroenceph. clin. Neurophysiol., 6, 65-84.

- (1958a). The effect of cortical stimulation on transmission through the cuneate nucleus in the anaesthetized rat. J. Physiol. (Lond.), 142, 2-3P.

- (1958b). The central control of sensory inflow. Proc. roy. Soc. Med., 51, 531-535.

Desmedt, J. E. (1963). Efferent olivo-cochlear gating of acoustic input and the resultant changes in auditory cortex potentials. $J$. Physiol. (Lond.), 165, 33P.

Doupe, J., Miller, W. R., and Keller, W. K. (1939). Vasomotor reactions in the hypnotic state. J. Neurol. Neurosurg. Psychiat., 2, 97-106.

Esdaile, J. (1846). Mesmerism in India, and its Practical Application in Surgery and Medicine. Longman, Brown, Green, and Longmans, London.

Ellingson, R. J. (1956). Brain waves and problems of psychology. Psychol. Bull., 53, 1-34.

French, J. D., Verzeano, M., and Magoun, H. W. (1953). A neural basis of the anesthetic state. A.M.A. Arch. Neurol. Psychiat., 69, 519-529.

Foltz, E. L., and Schmidt, R. P. (1956). The role of the reticular formation in the coma of head injury. J. Neurosurg., 13, 145-154.

Giblin, D. R. (1960). The effect of lesions of the nervous system on cerebral responses to peripheral nerve stimulation. Electroenceph. clin. Neurophysiol., 12, 262.

Gorton, B. E. (1949). The physiology of hypnosis. A review of the literature. Psychiat. Quart., 23, 317-343, 457-485.

Hagbarth, K. E., and Höjeberg, S. (1957). Evidence for subcortical regulation of the afferent discharge to the somatic sensory cortex in man. Nature (Lond.), 179, 526-527.

Halliday, A. M., and Mason, A. A. (1964). Cortical evoked potentials during hypnotic anaesthesia. Electroenceph. clin. Neurophysiol., 16,314 .

- - , and Mingay, R. (1961). Retroactive raising of a sensory threshold by a contralateral stimulus. Quart. J. exp. Psychol., 13, 1-11. , (1964). On the resolution of small time intervals and the effect of conduction delays on the judgement of simultaneity. Ibid., 16, 35-46.

—-, and Wakefield, G. S. (1963). Cerebral evoked potentials in patients with dissociated sensory loss. J. Neurol. Neurosurg. Psychiat., 26, 211-219.

Hernandez-Péon, R., and Donoso, C. M. (1957). Subcortical photically evoked electrical activity in the human waking brain. Excerpta Medica, 4th int. Congr. Electroenceph. clin. Neurophysiol., p. 155.

- - Guzmán-Flores, C., Alcaraz, M., and Fernández-Guardiola, A. (1957). Sensory transmission in visual pathway during 'attention' in unanesthetized cats. Acta neurol. Lat.-amer., 3, 1-8. Scherrer, H., and Jouvet, M. (1956). Modification of electric activity in cochlear nucleus during 'attention' in unanaethetized cats. Science, 123, 331-332 
Horn, G. (1960). Electrical activity of the cerebral cortex of the unanaesthetized cat during attentive behaviour. Brain, 83, 57-76.

-, and Blundell, J. (1959). Evoked potentials in visual cortex of the unanaesthetized cat. Nature (Lond.), 184, 173-174.

Hugelin, A., Dumont, S., and Paillas, N. (1960). Tympanic muscles and control of auditory input during arousal. Science, 131, 1371-1372.

Jouvet, M. (1961). Photically and somaesthetically subcortical electric activity in the human brain during attention. 5 th int Congr. Electroencephoencephalography and clinical Neurophysiol., Rome, 1961, p. 80. Excerpta med. Int. Congr. Ser. No. 37.

Larsson, L. E. (1953). Electroencephalographic responses to peripheral nerve stimulation in man. Electroenceph. clin. Neurophysiol., 5, 377-384.

- (1956). The relation between the startle reaction and the nonspecific EEG response to sudden stimuli with a discussion on the mechanism of arousal. Ibid., 8, 631-644.

Livingston, R. B. (1959). Central control of receptors and sensory transmission systems. In Handbook of Physiology: Section 1. Neurophysiology, vol. 1, pp. 741-760. American Physiological Society, Washington.
Lundholm, H. (1928). An experimental study of functional anesthesi as induced by suggestion in hypnosis. J. abnorm. soc. Psychotz $23,337-355$.

Mason, A. A. (1960). Hypnotism for Medical and Dental Practitioners Secker and Warburg, London.

- (1964). Hypnosis. In General Anaesthesia, edited by T. C. Gra and F. Evans, vol. 2, ch. 29. Butterworths, London.

McKenzie, J. S., and Beechey, N. R. (1962). The effects of morphine and pethidine on somatic evoked responses in the midbrain of the cat, and their relevance to analgesia. Electroenceph. clike Neurophysiol., 14, 501-519.

Ogden, T. E. (1960). Cortical control of thalamic somato-senso relay nuclei. Ibid., 12, 621-634.

Satterfield, J. H. (1962). Effect of sensorimotor cortical stimulatiơ upon cuneate nuclear output through medial lemniscus in cat J. nerv. ment. Dis., 135, 507-512.

Sears, T. A. (1959). Action potentials evoked in digital nerves by stimulation of mechanoreceptors in the human finger. Physiol. (Lond.), 148, 30-31P.

Titeca, J. (1938). Etude électrencéphalographique de deux ç d'anesthésie hystérique. J. belge Neurol. Psychiat. 38, 442. 478

Wolberg, L. R. (1948). Medical Hypnosis. Grune and Stratton, Ne星 York. 